\title{
The Journal of Extension
}

Volume 59 | Number 3

Article 10

$9-16-2021$

\section{Parental Awareness of Rural Adolescents' Dating Behaviors: Implications for Parent Education}

\author{
Sarah Taylor \\ California State University, Long Beach, sarah.taylor@csulb.edu \\ Yan Xia \\ University of Nebraska-Lincoln \\ Pooja Brar \\ Towson University
}

\section{(c) (1) (2)}

This work is licensed under a Creative Commons Attribution-Noncommercial-Share Alike 4.0 License.

\section{Recommended Citation}

Taylor, S., Xia, Y., \& Brar, P. (2021). Parental Awareness of Rural Adolescents' Dating Behaviors: Implications for Parent Education. The Journal of Extension, 59(3), Article 10. https://doi.org/10.34068/ joe.59.03.10

This Research in Brief is brought to you for free and open access by the Conferences at TigerPrints. It has been accepted for inclusion in The Journal of Extension by an authorized editor of TigerPrints. For more information, please contact kokeefe@clemson.edu. 


\title{
Parental Awareness of Rural Adolescents' Dating Behaviors: Implications for Parent Education
}

\author{
Sarah Taylor ${ }^{1}$, Yan $_{\text {Xia }}^{2}$, and Pooja Brar ${ }^{3}$
}

AUTHORS: ${ }^{1}$ California State University, Long Beach. ${ }^{2}$ University of Nebraska-Lincoln. ${ }^{3}$ Towson University.

\begin{abstract}
Most parent education programming focuses on educating parents with young children. Programming has focused less on supporting parents during their adolescent children's dating and sexual development. This study extends literature by exploring the extent to which rural parents are aware of their adolescent child's dating behaviors, as perceived by adolescents. Findings reveal three main themes: parents are fully aware of their child's dating behaviors, parents are aware they date but not aware of specific dating behaviors, and parents are not aware at all. Discussion includes practical implications for Extension and other parent education efforts in rural areas based on findings to support the development of healthy relationships during adolescence and into adulthood.
\end{abstract}

\section{INTRODUCTION}

Parent education serves to educate and support parents during different circumstances and developmental stages they encounter with their children (Bornstein, 2002). Hockersmith (2013) argues that Extension and other parent education personnel have a role in supporting families with topics related to adolescent relationship and sexual development. However, Extension programming aimed at parents of adolescents is missing the opportunity to guide parents in talking to their children about dating and sexual activity (Collins \& Fetsch, 2012). Research suggests that when parents are aware of and provide guidance to children's dating relationships, adolescents are less likely to engage in unhealthy relationship behaviors (Chan et al., 2016; Karofsky et al., 2001).

As Hockersmith (2013) explains, there may be both parents and Extension personnel in rural communities who feel uncomfortable with dating and sexual education material. Hockersmith (2013) makes the case that Extension is in a position to support families with healthy development and decision-making information. This article aims to address this gap, specifically in rural areas where communities are still reluctant to implement comprehensive sex education (Haley et al., 2013; O'Donnell et al., 2005), often due to the belief that relationship issues are a private matter (Hockersmith, 2013).

Overall, this study explores the following research question: To what extent do rural adolescents perceive their par- ents to be aware of their dating behaviors? Though a parental perspective is important, an adolescent perspective may provide further insight into how parental awareness is exhibited and displayed in the parent-child relationship; specifically, if this awareness translates to parental support and parent-child conversations on relationship health. Specific recommendations for parent education efforts are presented based on the findings.

\section{METHODS}

This research (a sub-study of a larger study on rural relationship health) used a qualitative design, which provided a deeper understanding of parental awareness of rural adolescent dating relationships. We selected 186 rural adolescents through schools and youth programs using convenience sampling. Extension personnel, youth program directors, and educators were emailed the purpose and goals of the study and asked to share a survey link with adolescents in their programs and classes. For the purposes of this study, any house or town that is not a part of an urban area (50,000 people or more) was considered rural (United States Department of Agriculture Rural Division, 2017). Table 1 provides an overview of participant demographics.

Qualitative data were collected through an open-ended survey question. Participants were asked to respond to the following: "Please explain the extent to which your parents are aware of your dating behaviors." Two researchers ana- 
Taylor, Xia, and Brar

Table 1. Overview of Sample Characteristics

\begin{tabular}{|c|c|c|c|}
\hline Variable & $\mathbf{M}$ & SD & $\%$ \\
\hline \multicolumn{4}{|l|}{ Gender } \\
\hline Male & & & 41.6 \\
\hline Female & & & 57.8 \\
\hline Agender & & & 0.6 \\
\hline Age & 17.91 & 1.42 & \\
\hline \multicolumn{4}{|l|}{ Race } \\
\hline White & & & 92.4 \\
\hline Black/African American & & & 4.7 \\
\hline American Indian/Alaska Native & & & 1.2 \\
\hline Asian or Pacific Islander & & & 1.2 \\
\hline \multicolumn{4}{|l|}{ Ethnicity } \\
\hline Hispanic/Latino & & & 5.2 \\
\hline Non-Hispanic/Non-Latino & & & 94.8 \\
\hline \multicolumn{4}{|l|}{ Sexual Orientation } \\
\hline Heterosexual & & & 94.8 \\
\hline Gay or lesbian & & & 0.6 \\
\hline Bisexual & & & 1.7 \\
\hline Unsure & & & 2.9 \\
\hline \multicolumn{4}{|l|}{ Population of Hometown } \\
\hline $0-499$ & & & 21.1 \\
\hline $500-4,999$ & & & 46.2 \\
\hline $5,000-50,000$ & & & 32.1 \\
\hline \multicolumn{4}{|l|}{ Housing Type } \\
\hline Own House & & & 92.9 \\
\hline Rent House & & & 5.9 \\
\hline Rent Apartment & & & 1.2 \\
\hline \multicolumn{4}{|l|}{ Receive Free/Reduced School Lunch } \\
\hline Yes & & & 14.6 \\
\hline No & & & 82.5 \\
\hline Do Not Know & & & 2.9 \\
\hline \multicolumn{4}{|l|}{ Adults Living Within Home } \\
\hline Mother & & & 84.9 \\
\hline Father & & & 78.5 \\
\hline Step-Mother & & & 3.2 \\
\hline Step-Father & & & 6.5 \\
\hline Grandparent & & & 2.2 \\
\hline \multicolumn{4}{|l|}{ Dating Behaviors } \\
\hline Had Not Begun Dating Behaviors & & & 20.0 \\
\hline Had Dated, But Not Currently in Relationship & & & 40.0 \\
\hline Currently in Relationship & & & 40.0 \\
\hline
\end{tabular}

Note. Percentages do not add up to $100 \%$ for some variables, as some participants responded to multiple options. 
lyzed participants' responses using inductive qualitative content analysis techniques, where the themes were derived from the data (Elo \& Kyngäs, 2008). The goal of inductive data analysis is to identify specific segments of text with a code and then combine these codes into broader themes for a comprehensive understanding of participants' perspectives (Chinn \& Kramer, 1999). Comments were coded based on the dominant messages conveyed in the participant's response (Eisner, 1998). Once all responses were coded, the codes were collapsed into patterns, and then further into themes. Intercoder reliability was used to ensure codes were dependable and findings were consistent with the data (Merriam, 2009). Two researchers each coded approximately $30 \%$ of the open-ended text. A Kappa of .92 was calculated, which exceeds the recommended value of .60 for inter-coder reliability (Everitt, 1996). In instances of disagreement between the two coders, the researchers discussed their perspectives until they arrived at a consensus.

\section{FINDINGS}

Most participant responses fall into one of three themes regarding parental awareness of their child's dating behaviors: 1) aware of all aspects of their dating relationships; 2) aware they date but not aware of their specific dating behaviors; or 3) not aware of their dating behaviors at all. Both male and female participants reported experiences in each of these three themes. Descriptions and excerpts of the three themes are presented below. Table 2 provides example responses from participants.

\section{AWARE OF EVERYTHING}

Almost half (46.0\%) of participants (44.1\% of males, $47 \%$ of females) perceived their parents to know "everything" about their dating relationships. These participants responded that their parents were aware of their intentions with their partner and the dating behaviors they chose to engage in. For instance, one participant explained that her parents were aware of the physical aspects of her relationship: "Parents knew what we planned and knew I wouldn't go too far" (Female, 18).

Some comments about parent awareness specifically relate to the rural context: "I live in a small community. Everyone knew we were dating" (Female, 19). Another participant explained how the rural culture impacts her dating behaviors:

Everyone, parents, brother, family members, employers, counselor, psychologist know about him. I previously went through 2 sexual assaults when I was 13 to 2 older men. People in my town have known about this, it's kind of hard when getting into relationships because I think some or majority think I am easy, until they know me. (Female, 19)

This participant associates the lack of anonymity in her community with her parents being aware of her current relationship.

Other participants mentioned how their parents were not initially aware of their dating behaviors, but have become fully aware over time. One participant mentioned, “They know pretty much everything eventually" (Male, 18). Another participant explained, "My parents know everything about my most recent dating behaviors but not my past" (Female, 18). Participants did not explain if this increase in awareness was due to parents learning more from observation or from children informing their parents.

\section{AWARE THEY DATE BUT NOT AWARE}

OF SPECIFIC BEHAVIORS

Many participants (38.0\% total; $26.5 \%$ males, $43.9 \%$ females) explained that their parents know about their partner and general details about their relationship, but are not aware of specific, intimate elements of the relationship. For instance, one participant described, "My parents know that I like girls or boys, and they know when I'm dating someone. That's usually all they know" (Female, 17). Another participant explained, "Now a days, no one knows what you do behind closed doors. They only see you in public and on dinner dates. But it's never known on the other half of what they do" (Male, 18).

Many participants' comments were rooted in them restricting their parents' access to intimate details of their relationships, such as sexual activity and relationship conflict. One participant mentioned, "They know about the relationships and the good things but not the fights and such" (Female, 18). A few participants perceived their parents to be unaware of the sexual intimacy details of their relationship. One participant explained, "My mom knows everything except that we have sex" (Female, 19). Overall, this theme was summed up by one participant's comment: "They can know if they want to but there is a line that shouldn't be crossed" (Female, 18). Many adolescents from this study reported that they control the extent to which their parents are aware of their dating behaviors. If parents ask about their child's dating behaviors, they are informed of general dating behaviors, but are not informed of more intimate and sexual details.

\section{NOT AWARE AT ALL}

Finally, approximately $16.0 \%$ of participants (29.4\% males, $9.1 \%$ females) said that their parents were not aware to any extent of their dating behaviors. Some participants mentioned that their parents do not know because adolescents perceive them to be indifferent towards the relationships and thus do not discuss their relationships with them. One par- 
Taylor, Xia, and Brar

Table 2. Example Responses from Participants

\begin{tabular}{|c|c|}
\hline Most Common Themes & Examples \\
\hline \multirow{7}{*}{ Aware of Everything } & "Parents knew what we planned and knew I wouldn't go too far." \\
\hline & "Everyone, parents, brother, family members, employers, counselor, psychologist know \\
\hline & about him. I previously went through 2 sexual assaults when I was 13 to 2 older men. \\
\hline & People in my town have known about this, it's kind of hard when getting into relation- \\
\hline & ships because I think some or majority think I am easy, until they know me." \\
\hline & "My parents know everything about my most recent dating behaviors but not my past." \\
\hline & "I live in a small community everyone knows." \\
\hline \multirow{6}{*}{$\begin{array}{l}\text { Aware They Date but not Aware of } \\
\text { Specific Behaviors but not specific } \\
\text { behaviors }\end{array}$} & $\begin{array}{l}\text { "My parents know that I like girls or boys, and they know when I'm dating someone. } \\
\text { That's usually all they know." }\end{array}$ \\
\hline & "Now a days no one knows what you do behind closed doors. They only see you in public \\
\hline & and on dinner dates. But it's never known on the other half of what they do." \\
\hline & "They know about the relationships and the good things but not the fights and such." \\
\hline & "My mom knows everything except that we have sex." \\
\hline & "They can know if they want to but there is a line that shouldn't be crossed." \\
\hline \multirow{2}{*}{ Not Aware at All } & "They don't really notice that I'm dating anyone." \\
\hline & "If they don't ask, I don't tell." \\
\hline
\end{tabular}

ticipant said, "They don't really notice that I'm dating anyone" (Male, 18). Another participant said, "If they don't ask, I don't tell" (Male, 18). Overall, this theme suggests that for approximately 1 in 6 parents, they do not inquire or initiate dialogue unless their child offers information.

\section{DISCUSSION AND RECOMMENDATIONS FOR PARENT EDUCATION}

Overall, findings expand the literature on parental awareness of rural adolescent dating relationships. Findings suggest that adolescents from this study perceive varying levels of awareness among their parents and that many adolescents perceive their parents to have limited awareness of their dating relationships. Findings pertain to adolescents' perceptions; while parents may have different perspectives, the adolescent perspective may shed light on how this awareness manifests, indicating the extent parents are willing to communicate (both verbally and nonverbally) about these relationships in a way that is recognized by adolescents. Participants' comments highlight the need for rural parents to have access to resources on parent-adolescent communication regarding intimate relationships and sexual involvement. The following recommendations are presented for parent education efforts in rural areas based on findings.

First, comments in this study indicate that adolescents growing up in rural environments are sexually active, despite beliefs that often inaccurately suggest that rural adolescents choose to remain abstinent (Greslé-Favier, 2010). Findings indicate that some adolescents choose not to confide in their parents about their intimate relationships unless directly asked by a parent. This is an important consideration in relation to topics of relationship discord and possible dating abuse. Extension and other parent education teams may benefit their communities by disseminating prevalence rates of adolescent dating activity and sexual risk-taking through print resources and other educational campaigns (Thomas et al., 2013). Creators of these resources may want to highlight that many adolescents do not inform their parents of their dating involvement, relationship conflict, and sexual activity. This information may assure parents of the relevance and urgency of communicating with their child about these topics.

Second, participants' comments suggest that parents may be unsure how to initiate dialogue about their child's dating relationships and sexual activity. For parents who do initiate dialogue, participants' comments suggest that some methods used may not be well received by their children. Parent education efforts should share ideas on how and when parents can start these conversations. For instance, parents can learn open-ended conversation starters like, "I saw you talking to Maria after school. How do you feel about Maria?" or "What do you think they're talking about in this song?" if a sexually explicit song comes on the radio. Extension and other parent education teams can connect parents to reliable websites with sexual health information that parents and children can view together. Participant comments indicated that "there is a line that shouldn't be crossed" with regard to the extent children will share with their parents. Parent education can provide parents with skills on how to respond if their child shuts down a conversation, such as bringing up the conversation again a little bit at a time and asking if 


\section{Parental Awareness of Rural Adolescents' Dating Behaviors: Implications for Parent Education}

their child has any questions about a particular topic when it is brought up around them (e.g., movie, advertisement). Even if adolescents are not responsive to these conversations at times, equipping parents with the skillset to support on-going opportunities for dialogue will benefit adolescents (Dyson \& Smith, 2012).

Finally, even if children are open about their relationships with their parents, findings suggest they may not verbally acknowledge negative aspects. The idea that "everyone knows" was conveyed by participants. The belief that "everyone knows" may be inaccurate and might cause parents to think that their children automatically know who would make a safe and healthy partner and who would not. Parents should be reminded that this developmental stage is novel for adolescents and that they need guidance in developing and maintaining healthy relationships (Shtarkshall et al., 2007). Parent education can incorporate conversation starters for parents to use, such as: "What do you think you would do if someone you were dating acted like that boy in this movie?" Parent education can also review healthy relationship content and current trends that parents can then apply to their dialogue with their children, such as communication methods, conflict resolution, boundaries, and consent.

\section{LIMITATIONS AND CONCLUSION}

This study has limitations that should be acknowledged. Many participants' responses were lacking depth due to the placement of the open-ended question at the end of the survey. Future research should explore alternative methods for collecting in-depth qualitative data among adolescents on dating and sexual experiences, such as interviews or surveys solely containing open-ended questions. These methods should still be sensitive. Research should also explore parental awareness with parent samples and investigate differences in perceptions of parental awareness between parents and children. Additionally, the sample used in this study lacked diversity due to the heterogeneous population of the rural communities where sampling occurred. Future research should collect data among varying racial, ethnic, sexual orientation, and age groups of adolescents.

Overall, Extension serves families and communities with many topics, but one in particular is supporting the healthful development of youth (Smathers et al., 2019). Consequently, Extension has an opportunity to support families through the sexual and relationship development stage of childhood and adolescence. This study aimed to identify the extent adolescents perceive their parents to be aware of their relationship behaviors to provide recommendations for Extension and other parent education efforts. Future research and Extension programming should build off this study.

\section{REFERENCES}

Bornstein, M. H. (Eds). (2002). Handbook of Parenting: Volume 4 Social Conditions and Applied Parenting. Lawrence Erlbaum Associates.

Chan, A. E., Adler-Baeder, F. M., Duke, A. M., Ketring, S. A., \& Smith, T. A. (2016). The role of parent-child interaction in community-based youth relationship education. The American Journal of Family Therapy, 44(1), 36-45. https://doi.org/10.1080/01926187.2016.1 145079

Chinn, P. L., \& Kramer, M. K. (1999). Theory and nursing integrated knowledge development ( $5^{\text {th }}$ ed.). Mosby.

Collins, C. L., \& Fetsch, R. J. (2012). A review and critique of 16 major parent education programs. Journal of Extension, 50(4). https://archives.joe.org/joe/2012 august/a8.php

Dyson, S., \& Smith, E. (2012). 'There are lots of different kinds of normal': Families and sex education-styles, approaches and concerns. Sex Education, 12(2), 219229. https://doi.org/10.1080/14681811.2011.609053

Eisner, E. W. (1998). The enlightened eye: Qualitative inquiry and the enhancement of educational practice. Merrill.

Elo, S., \& Kyngäs, H. (2008). The qualitative content analysis process. Journal of Advanced Nursing, 62(1), 107-115. http://doi.org/10.1111/j.1365-2648.2007.04569.x

Everitt, B. (1996). Making sense of statistics in psychology: A second-level course. Oxford University Press.

Greslé-Favier, C. (2010). The legacy of abstinence-only discourses and the place of pleasure in US discourses on teenage sexuality. Sex Education, 10(4), 413-422. https://doi.org/10.1080/14681811.2010.515098

Haley, T., Puskar, K., Terhorst, L., Terry, M. A., \& Charron-Prochownik, D. (2013). Condom use among sexually active rural high school adolescents personal, environmental, and behavioral predictors. The Journal of School Nursing, 29(3), 212-224. http://doi. org/10.1177/1059840512461282

Hamilton, B. E., Rossen, L. M., \& Branum, A. M. (2016). Teen birth rates for urban and rural areas in the United States, 2007-2015. NCHS Data Brief, (264), 1-8.

Hockersmith, L. D. (2013). Sextension? Journal of Extension, 51(1). https://archives.joe.org/joe/2013february/ comm1.php

Karofsky, P. S., Zeng, L., \& Kosorok, M. R. (2001). Relationship between adolescent-parental communication and initiation of first intercourse by adolescents. Journal of Adolescent Health, 28(1), 41-45. http://doi.org/10.1016/ s1054-139x(00)00156-7

Merriam, S.B. (2009). Qualitative Research. A Guide to Design and Implementation. Jossey-Bass.

O’Donnell, L., Stueve, A., Agronick, G., Wilson-Simmons, R., Duran, R., \& Jeanbaptiste, V. (2005). Saving sex for 
later: An evaluation of a parent education intervention. Perspectives on Sexual and Reproductive Health, 37(4), 166-173. http://doi.org/10.1363/psrh.37.166.05

Shtarkshall, R. A., Santelli, J. S., \& Hirsch, J. S. (2007). Sex education and sexual socialization: Roles for educators and parents. Perspectives on Sexual and Reproductive Health, 39(2), 116-119. https://doi.org/10.1363/3911607

Smathers, C., Toomey, M., Washburn, L., Johnston, K., Iaccopucci, A. M., Johannes, E., \& Ravola, M. (2019). Positive youth development for health: Extension's readiness for multilevel public health approaches. Journal of Extension, 57(1). https://tigerprints.clemson.edu/ joe/vol57/iss $1 / 22 /$

Thomas, R., Homawoo, B. B., McClamroch, K., Wise, B., \& Coles, F. B. (2013). Community attitudes about discussing sexual health: Assessing public opinion of local STD prevention campaigns. Public Health Reports, 128(2_suppl1), 73-80. https://doi. org/10.1177/00333549131282S108

United States Department of Agriculture Rural Division. (2017). Business \& industry loan guarantees. https:// www.rd.usda.gov/programs-services/businessindustry-loan-guarantees 